IJBPAS, December, 2021, 10(12): 4342-4355

ISSN: $2277-4998$

International Journal of Biology, Pharmacy

and Allied Seiences (IJBPAS)

'A Bridge Betuben caboratory and QRendo'

WwW.ijbpas.com

NOSOCOMIAL OUTBREAK BY COLISTIN-RESISTANT KLEBSIELLA PNEUMONIA:

A CASE REPORT

\title{
GUPTA $M^{1}$, PRADHAN B ${ }^{2}$, BEHERA BC ${ }^{3}$, NAIK AK ${ }^{4}$, SINGH SK $^{5 *}$
}

1: TATA Main Hospital, Jamshedpur-831001, Jharkhand, India

2: S. K. Dash Centre of Excellence of Biosciences and Engineering \& Technology, Indian Institute of Technology Bhubaneswar, Arugul, Jatni-752050, Odisha, India

3: Department of Biotechnology, North Orissa University, Baripada 757003, Odisha, India

4: National Institute of Science Education and Research Bhubaneswar, Jatni-752050, Odisha, India

5: Department of Biotechnology, ARKA Jain University, Jamshedpur, Jharkhand-832108, India

*Corresponding Author: Santosh Kumar Singh: E Mail: thatoinou@gmail.com

Received 18 ${ }^{\text {th }}$ Feb. 2021; Revised 19 ${ }^{\text {th }}$ Mar. 2021; Accepted 15 ${ }^{\text {th }}$ April. 2021; Available online $1^{\text {st }}$ Dec. 2021

https://doi.org/10.31032/IJBPAS/2021/10.12.5751

\begin{abstract}
The dramatic increase of resistance in Klebsiella pneumoniae (K. pneumoniae) due to the misuse of antibiotics poses one of the most significant health threats and is a global health concern. Colistin, a last resort antibiotic is used extensively to treat carbapenem-resistant Klebsiella pneumoniae infections. Present research carried out to analyze the molecular mechanism, clonal types and outcomes of the infections caused by colistin-resistant $K$. pneumoniae in neonates during an outbreak in neonate intensive care unit. Twenty eight cases of colistin-resistant, carbapenem-resistant K. pneumoniae were identified between March and April 2016. Isolates were genotyped using multi-locus sequence typing and molecular mechanism of colistin resistance was ascertained. All the colistin resistant $K$. pneumoniae isolated from neonates during outbreak have insertional inactivation by ISL3 family transposes in the $\operatorname{mgr\mathrm {B}}$ gene and were clonally related belong to ST11. PCR screening confirmed the presence of the bla $b l a_{\mathrm{SHV}-34}$ genes. The observed mortality was $35.7 \%$ in two month periods. The present baseline
\end{abstract}


report of colistin-resistant $K$. pneumoniae ST11 outbreak suggested the emergence of clones with this phenotype that required paramount importance for future health monitoring and assessment.

\section{Keywords: Antibiotics, $\beta$-lactamase, colistin-resistance, Klebsiella pneumoniae, plasmid INTRODUCTION}

Klebsiella pneumoniae has emerged as a superbug and poses as one of the world's greatest health threats [1]. It is the causative agent of a variety of diseases, commonly including urinary tract, soft tissue infections, bacteremia, and pneumonia; however, community-acquired invasive infections have also emerged as of late in the form of a pyogenic liver abscess, brain abscess, meningitis and ankylosing spondylitis [2-3]. Eradication of this superbug is challenging as it has acquired resistance to almost all available antibiotics and is consequently associated with high morbidity and mortality, thus it has been included among the six multidrug-resistant ESKAPE pathogens (Enterococcus faecium, Staphylococcus aureus, Klebsiella pneumoniae, Acinetobacter baumannii, Pseudomonas aeruginosa, and Enterobacter species) [4]. Neonates are more vulnerable to infection due to their immature immune system. Low birth weight, prematurity, febrile illness in the mother, rupture of membranes, unhygienic conditions, delays in recognition and prolong hospitalization are some recognized risk factors. In India, neonatal septicemia reported incidence rate of 30 cases per 1000 live births, with $K$. pneumoniae as the most frequently isolated pathogen in both intramural births $(32.5 \%)$ and extramural neonates (27\%) [5]. Use of cephalosporin and carbapenem leaped forward the fight against infections caused by K. pneumoniae. However, co-production of multiple $\beta$-lactamases, especially ESBLs (e.g. bla $a_{\mathrm{SHV}}, b l a_{\mathrm{TEM}}$ and/or $\left.b l a_{\mathrm{CTX}}\right)$ and carbapenemase (bla $a_{\mathrm{KPC}}$ and/or bla $\left.{ }_{\mathrm{OXA}}\right)$, in $K$. pneumoniae has been reported from many countries, rendering $\beta$-lactam antibiotics completely futile [6-8]. The situation is further complicated as extended-spectrum $\beta$ lactamase (ESBL)-producing K. pneumoniae isolates exhibited very high (up to 56\%) resistance to quinolones [9].

Due to the unavailability of therapeutic alternatives for the treatment of carbapenem resistant $K$. pneumoniae (CRKP), colistin has been extensively used instead. Colistin sulfate (CS) is used for oral and topical therapy, whereas colistin methanesulfonate sodium (CMS) is used for parenteral and aerosol therapy [10-11]. Colistin being positively charged, alters the 
permeability of the bacterial cell membrane by displaying divalent cations, $\mathrm{Ca}^{2+}$ and $\mathrm{Mg}^{2+}$, from the phosphate groups of lipid A, thus causing an outflow of cell contents which ultimately results in bacterial death [12]. However, with excessive use, colistin resistance in $K$. pneumoniae began to increase, which highlights an emerging threat in the treatment of healthcare-related infections [13- 14]. PhoP/PhoQ and PmrA/PmrB are the main systems responsible for modification of the lipopolysaccharide (LPS) layer. Changes in these regulatory systems cause colistin resistance. Insertional inactivation/mutation of the $m g r \mathrm{~B}$ gene, which encodes the key regulatory protein of $\mathrm{PhoP} / \mathrm{PhoQ}$ system, or the presence of a plasmid mediated $\mathrm{mcr}-1$ gene are the primary mechanisms driving colistin resistance [15-17].

Between March-July 2016, an outbreak of colistin resistant $K$. pneumoniae bacteremia was reported in the neonatal intensive care unit, Jamshedpur, Jharkhand [18]. Keeping the progressive resistance mechanism of $K$. pneumoniae in mind which is a global health concern, the present research investigation has been carried out to analyze the molecular mechanism of colistin resistance, clonal types, clinical futures and outcomes of the infections caused by colistin-resistant $K$. pneumoniae isolated from neonates during this outbreak. Our findings will set the stage for future research on this emerging health crisis.

\section{MATERIALS AND METHODS}

\section{Bacterial Isolates}

Thirty (28 from neonates and 2 from hospital environment) non-duplicate colistinresistant carbapenem-resistant $K$. pneumoniae $\left(\mathrm{COL}^{\mathrm{R}}-\mathrm{CRKP}\right)$ isolates from the neonatal intensive care unit of a tertiary care hospital (Jharkhand, India) during an outbreak were included in this study. One $\mathrm{ml}$ of blood was drawn from the neonates suspected to have sepsis and inoculated in the BacT/ALERT (bioMerieux, USA) microbial detection system. After the prediction of an outbreak, surveillance swabs from nursery (air, warmer, suction, IV/PIC line and oxygen nozzle), gynecology OT (table, light and instruments) and labor room were taken for culture. Random hand swabs of staff, doctors and mothers were also taken for culture. Identification and antibiotic susceptibility of isolates were determined by aVITEK ${ }^{2} 2$ compact system (bioMerieux, USA) using the ID-GNB and AST-N280 cards in accordance with the manufacturer's instructions. The antimicrobial susceptibility testing card included the following antibiotics: ampicillin (AMP), cefuroxime 
(CXM), ceftriaxone (CRO), cefepime (FEP), imipenem (IPM), meropenem (MEM), cefoperazone/sulbactam (CSS), piperacillintazobactam (TZP), amoxicillin-clavulanic acid (AMC), ciprofloxacin (CIP), trimethoprim-sulfamethoxazole (SXT), amikacin (AMK), gentamicin (GEN), nitrofurantoin (NIT), ertapenem (ERT), cotrimoxazole (COT) and colistin (COL). Ertapenem resistance was defined as a MIC of $\geq 8 \mathrm{mg} / \mathrm{l}$ and colistin resistance was defined as a MIC of $\geq 4 \mathrm{mg} / \mathrm{l}$ [19]. Escherichia coli ATCC 25922 and Klebsiella pneumoniae ATCC 700603 were used as quality control strains for each batch of MIC tests

\section{Patients and clinical epidemiology}

Demographic data such as gender, age, clinical diagnosis, location, clinical outcome, the time of admission, the time of discharge and the length of hospital stay were extracted from the patient administration system.

\section{Detection of $\beta$-lactamase genes}

Phenotypic detection of ESBLs, MBLs and carbapenemase was carried out using a double disk synergic test, and imipenem EDTA double disc synergy test and Modified Hodge test (MHT) respectively, following the protocol as described by CLSI 2014 manual [20]. The phenotypic detection of $A m p \mathrm{C}$ was performed using a ceftazidime-boronic acid combined disc diffusion test as described by Yilmaz et al. [21]. PCR amplification was carried out in a thermal cycler (Eppendorf, Germany) to detect the genes encoding for bla $_{\mathrm{TEM}}, \quad b l a_{\mathrm{SHV}}, \quad b l a_{\mathrm{IMP}}, \quad b l a_{\mathrm{VIM}}, \quad b l a_{\mathrm{NDM}-1}$, bla $a_{\mathrm{OXA}-48}, b l a_{\mathrm{KPC}}$ and $A m p \mathrm{C}$ according to their respective product size. PCR products were separated in a $1 \%$ agarose-TAE gel containing ethidium bromide and visualized in a Chemidoc imager (Bio-Red, USA).

\section{PCR amplification of mgrB and mer-1 genes}

PCR amplification of the $m g r \mathrm{~B}$ gene and $m c r-1$ gene were carried out to determine the colistin resistance mechanism. The presence of plasmid DNA of all the $K$. pneumoniae isolates was screened using QIAGEN plasmid mini kit (QIAGEN GmbH, Germany). Amplified PCR products were purified with a QIAquick PCR Purification Kit (QIAGEN) and sequenced with an ABI 3100 Sequencer (Applied Biosystems, Foster City, CA). The nucleotide and deduced protein sequences were analyzed using the NCBI website (http://www.ncbi.nlm.nih.gov). The insertion sequence (IS) was analyzed using the IS finder website (http://wwwis.biotoul.fr).

\section{Molecular typing}


Strain typing of $K$. pneumoniae isolates was performed by ERIC-PCR using primer setERIC-2/ERIC-1026 according to Munoz et al. [22]. Multilocus sequence typing of isolates were performed as described by Diancourt et al. [23] and analyzed using the MLST website for $K$. pneumoniae

(http://www.pasteur.fr/recherche/genopole/P F8/mlst/Kpneumoniae.html). All the seven house-keeping gene sequences were submitted to get the gene bank accession number.

\section{RESULTS AND DISCUSSION}

A total of 28 colistin resistant $K$. pneumoniae were isolated between March and April 2016 from the blood culture of neonates admitted to neonatal intensive care unit [Table1]. Out of 28 neonates, 57\% $(n=16)$ were males and $43 \%(n=12)$ were females. In addition two more colistin resistant $K$. pneumoniae strains (EKpCR1 and EKpCR2) were isolated from the gynecological oxygen nozzle and suction of the operation table (OT) of the same hospital. However, all the $K$. pneumoniae isolates showed uniform antibiogram, pattern and resistance to the first and second line of cephalosporins, $\quad \beta$-lactam $/ \beta$-lactamase inhibitor combination drugs, carbapenems, aminoglycosides, quinolones and colistin.
The only drugs which were sensitive in all of the isolates were tigecycline and cotrimoxazole, revealed that all of the isolates belonged to a single clone.

The isolates were phenotypically negative for $\mathrm{ESBL}, \mathrm{MBL}$ and $A m p \mathrm{C}$ production, whereas determined to be positive for the production of carbapenemases by a modified Hodge test. PCR screening confirmed the presence of the bla $_{O X A-48}$ and bla $_{\mathrm{SHV}-34}$ genes.

All isolates in the present study contain plasmids. However, PCR amplification of $m c r-1$ gene was negative for all isolates. PCR amplification targeting $m g r \mathrm{~B}$ gene was carried out to determine the presence of colistin resistance. Targeted 250bp PCR amplification gave an amplicon of 510bp [Figure 1], indicating the presence of an insertion sequence. Sequence analysis of the amplicon revealed that the ISL3 family transposase (ISKpn25 ORF4) of $363 \mathrm{bp}$ targeted in the reverse orientation, downstream of $133 \mathrm{bp}$ of $m g r \mathrm{~B}$ gene led to insertional inactivation [Figure 2]. The NCBI accession number of the seven housekeeping gene sequences used for MLST and the $m g r \mathrm{~B}$ gene sequence of colistin resistant carbapenem resistant $K$. pneumoniae CKpCR1 were MG367191-MG367198. 
On the basis of ERIC-PCR band similarity [Figure 3], K. pneumoniae strains were deemed to be representative of a clonal. Multi-locus sequence typing showed that isolates belonged to ST11 with allelic variation $3,3,1,1,1,1,4$.

In this study we described and characterized a clonal outbreak of $K$. pneumoniae bacteremia in the NICU of a tertiary care hospital in the state of Jharkhand, India. All of the neonates in the study exhibited respiratory distress, low platelets associated with diminished spontaneous activity and feeding intolerance, positive blood culture for bacteria with similar culture characteristics and antibiotic resistance pattern. The observed mortality was $35.7 \%$ over two month's period. Majhi et al. [18] have reported detailed clinical parameters during this outbreak, including the severity of illness, risk factors such prematurity, birth asphyxia, babies who had surgery, double volume exchange transfusion and prior antibiotic usages [18]. This outbreak was caused by a colistin resistant $b a_{\text {OXA-48 }}$ and bla $a_{\text {SHV-34 }}$ producing $K$. pneumoniae ST11 that was susceptible only to tigecycline and co-trimoxazole. Proper surveillance and actions like removal of gynecological OT oxygen nozzle and suction, lead to overcome the outbreak.
At present, reserved antibiotic colistin and newly developed glycylcycline antibiotic tigecycline are of the few available antibiotics for treating carbapenem-resistant bacteria. Following excessive use, bacteria have progressively developed resistance toward colistin. In 2004, the first clinical outbreak of colistin resistant $K$. pneumoniae was reported in Greece [24]. Since then, the emergence of colistin-resistant $K$. pneumoniae was reported from various part of the world [25]. Several recent studies highlight the loss-of-function mutations of the $m g r \mathrm{~B}$ gene responsible for the emergence of colistin resistance in $K$. pneumoniae. However, other mechanisms, such as the role of efflux pump and plasmid mediated colistin resistance protein $m c r-1$ were reported to be associated with colistin resistance in $K$. pneumoniae [26-27]. In the present study, we found insertional inactivation of the $m g r \mathrm{~B}$ gene by transposase of ISL3 family that might be responsible for colistin resistance in all the K. pneumoniae isolates. Similar ISL3, a transposable restriction-modification system of 8154 nucleotides inserted in $m g r B$ nucleotide position 133 was reported in colistin resistant $K$. pneumoniae ST258 isolated from two Italian and eight Greek patients [28]. They reported that ISL3 was located on $\mathrm{pKpQIL-like} \mathrm{plasmids} \mathrm{and} \mathrm{may}$ 
transpose into the chromosome. Single locus variant of ST11, colistin resistant $K$. pneumoniae ST258 with the insertional inactivation of $m g r B$ gene by an IS5-like element was reported [15].

In clinical isolates of Klebsiella pneumoniae, colistin resistance has been reported to be mainly associated with the sequence types ST 258, ST 512 and ST147 [29-30]. However, in our study, colistin resistant $K$. pneumoniae has been observed in sequence type ST11. In a SMART surveillance program during 2008 and 2009,
K. pneumoniae ST11 producing bla OXA-48- $^{-}$ like and NDMs were reported from India and many parts of the world [31]. In India, colistin resistant $K$. pneumoniae ST11 were reported from a tertiary care hospital carried $\beta$-lactam, fluoroquinolones, aminoglycoside and fosfomycin resistant genes on the genomic DNA [32]. We found that all the isolated $K$. pneumoniae has ESBL (bla $\left.{ }_{\mathrm{SHV}-34}\right)$ and carbapenemase ( bla $_{\text {OXA-48 }}$ ) genes though the fluoroquinolones and aminoglycoside resistance study were not carried out in the present study.

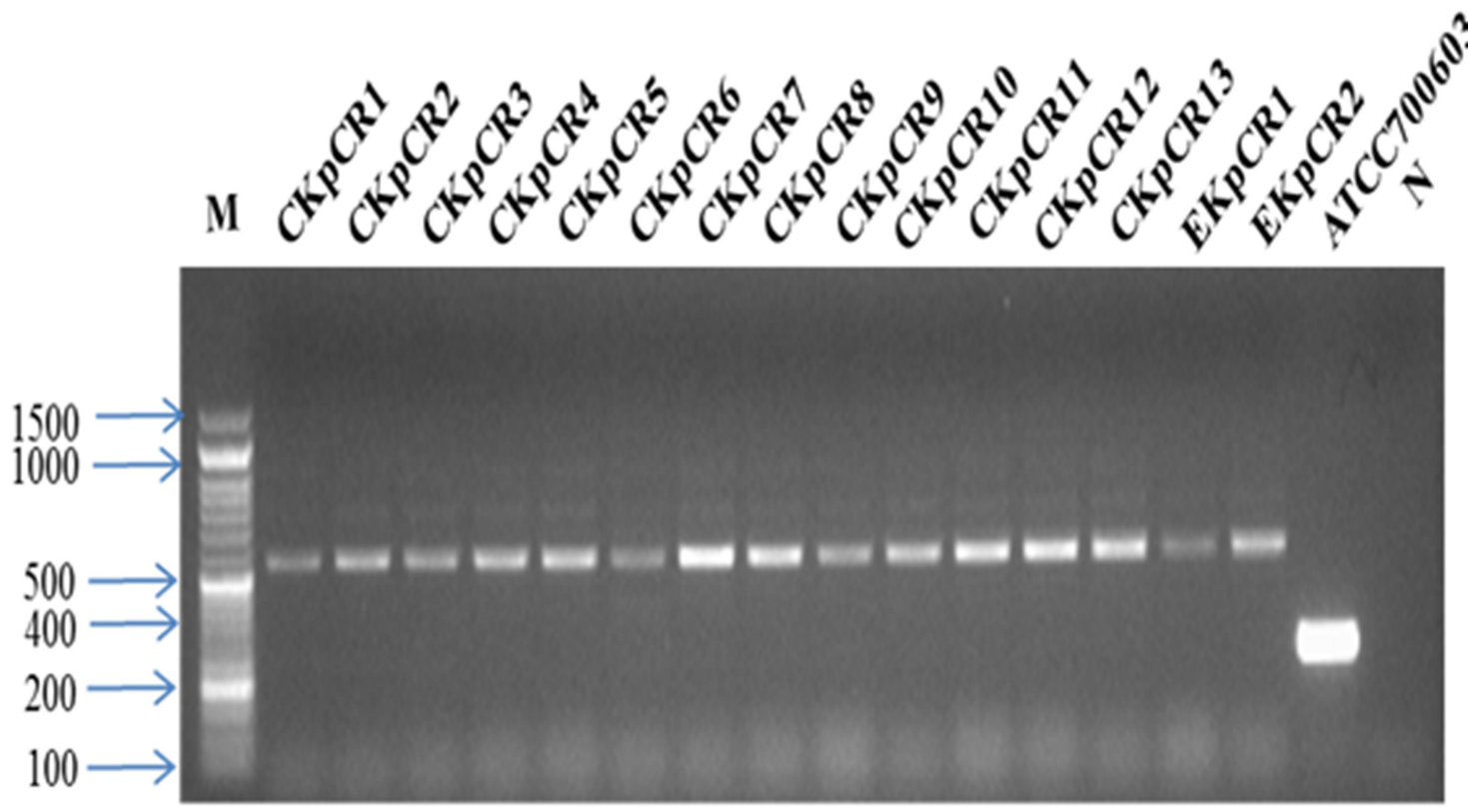

Figure 1: PCR amplification of $m g r B$ gene. Lanes 1-13 were colistin resistant $K$. pneumoniae isolated from neonates and Lane 14-15 were colistin resistant $K$. pneumoniae isolated from hospital environment. $M$ : DNA ladder (NEB, size as indicated) and N: Non template control 


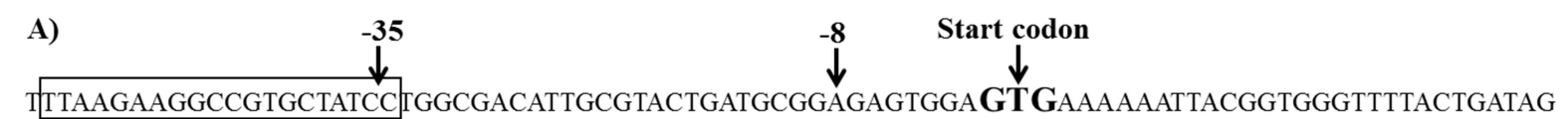
TCATCATAGCAGGCTGCCTGTTGCTGTGGACTCAGATGCTTAACGTAATGTGCGACCAGGATGTTCAGTTTTTCAGCGGCATTTGC ACTATTAATAAATTTAGGCTATTTGCATTCTAGGGTTGGAATTCATCCATTCTAACCCTTAATTCTTAGTCGGACAAAAAGCTGCTTC TGGTTGGATTTTTCTGCTTTTCACCACCCTGCGAAAATCTAACATTGGTTGGATTCTCAGACGCGCCCTCTCTCGCGTTAATCCAAC TCTCCACCTTCTGCCTGCTTCAACAATGTCGGAATGTGCGGTCCATACTCGACCTTGCCTCGTCCTGCTCGAATACCACTGCCAAC CTTGCGGGCTTCTTTGGAGTACAACGTCTTTGCACGGATGATCTCATAGCTATAACCCCGACCTAACCGGTTGGACATCTTGATCAA GCCGTTGAGCCCTTCGGTATAGCCATTGGTGC-TAGAATGAACGCCTA

B)

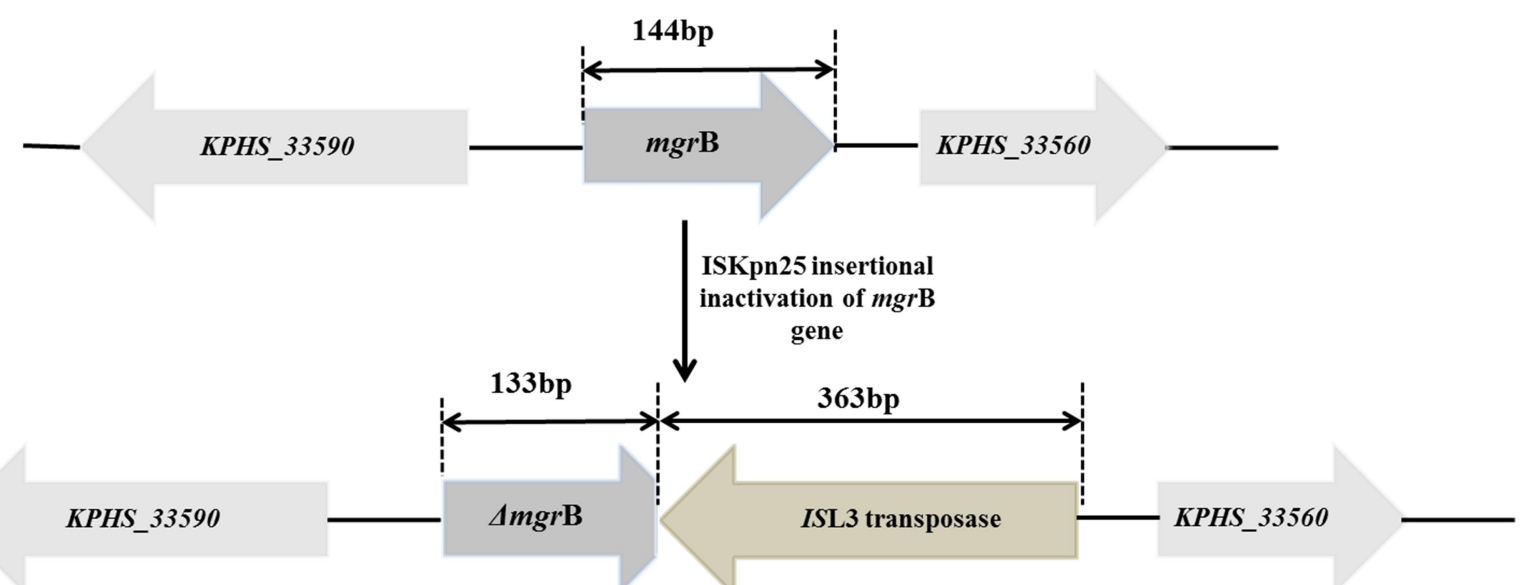

Figure 2: Insertional inactivation of $m g r B$ gene. A) Sequence of $\Delta m g r B$ gene and ISKpn25-like insertional sequence. The $m g r B$ start codon is in bold, grey shaded area indicates ISKpn25 sequence (B) Schematic representation of insertional inactivation of $m g r B$ gene by ISKpn25 insertion sequence

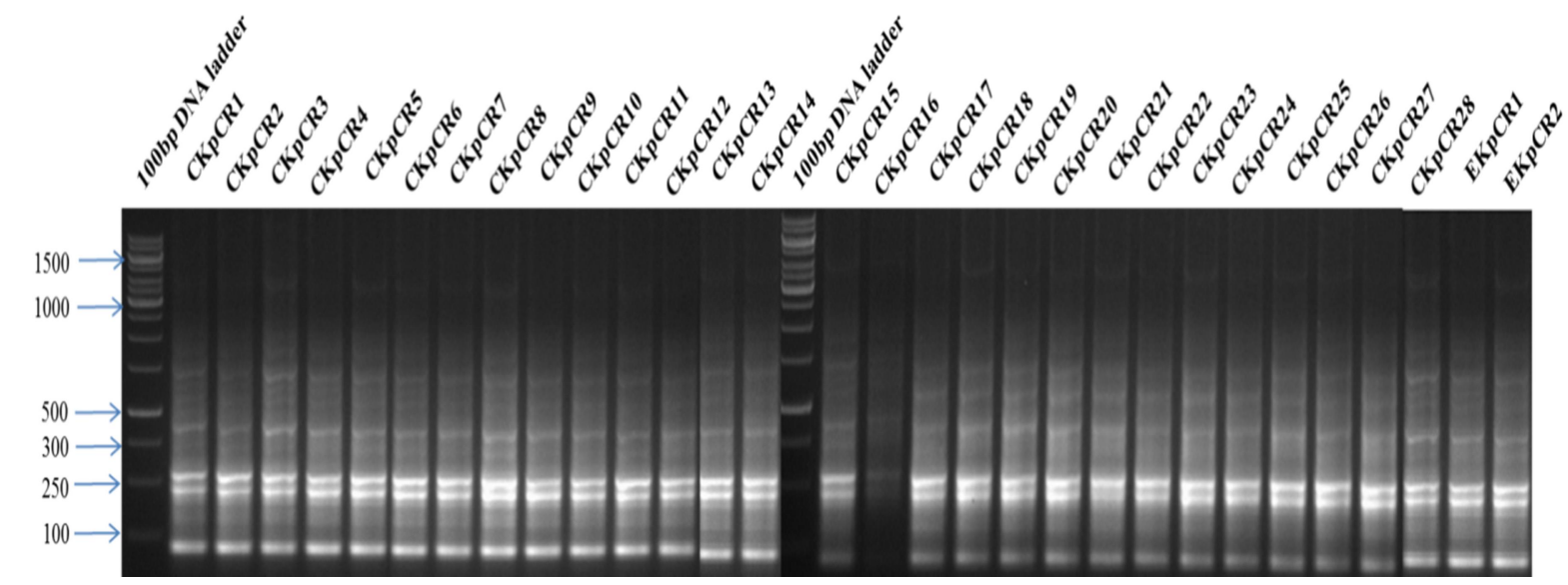

Figure 3: ERIC-PCR of colistin resistant and carbapenem-resistant Klebsiella pneumoniae isolated from neonates and hospital environment during outbreak. Klebsiella pneumoniae isolated from neonates were designated as CKpCR and hospital environment isolates were designated as EKpCR 
Table 1: Isolates ID and detail of the patients during outbreak

\begin{tabular}{|c|c|c|c|c|c|c|c|c|}
\hline \multirow{2}{*}{ Isolates ID } & \multirow{2}{*}{$\begin{array}{c}\text { Date of } \\
\text { isolation of } K . \\
\text { pneumoniae }\end{array}$} & \multicolumn{4}{|c|}{ MIC(mg/l) } & \multirow{2}{*}{$\begin{array}{c}\text { Gender of } \\
\text { patient }\end{array}$} & \multirow{2}{*}{$\begin{array}{c}\text { Hospital } \\
\text { stay of } \\
\text { patient } \\
\text { (days) }\end{array}$} & \multirow{2}{*}{$\begin{array}{c}\text { Outcome of } \\
\text { patient }\end{array}$} \\
\hline & & Col & ERT & MER & TGC & & & \\
\hline CKpCR1 & 2-Mar-16 & $>16$ & $>8$ & $>16$ & 2 & $\mathbf{F}$ & 33 & Alive \\
\hline CKpCR2 & 26-Mar-16 & $>16$ & $>8$ & $>16$ & 2 & M & 7 & Alive \\
\hline CKpCR3 & 28-Mar-16 & $>16$ & $>8$ & $>16$ & 2 & $\mathbf{F}$ & 5 & Dead \\
\hline CKpCR4 & 10-Apr-16 & $>16$ & $>8$ & $>16$ & 2 & M & 7 & Dead \\
\hline CKpCR5 & 10-Apr-16 & $>16$ & $>8$ & $>16$ & 2 & M & 23 & Alive \\
\hline CKpCR6 & 1-Mar-16 & $>16$ & $>8$ & $>16$ & 2 & $\mathbf{F}$ & 4 & Alive \\
\hline CKpCR7 & 16-Apr-16 & $>16$ & $>8$ & $>16$ & 2 & $\mathbf{F}$ & 26 & Dead \\
\hline CKpCR8 & 5-Mar-16 & $>16$ & $>8$ & $>16$ & 2 & M & 5 & Dead \\
\hline CKpCR9 & 21-Apr-16 & $>16$ & $>8$ & $>16$ & 2 & $\mathbf{F}$ & 2 & Alive \\
\hline CKpCR10 & 16-Apr-16 & $>16$ & $>8$ & $>16$ & 2 & F & 29 & Alive \\
\hline CKpCR11 & 14-Mar-16 & $>16$ & $>8$ & $>16$ & 2 & M & 10 & Alive \\
\hline CKpCR12 & 26-Mar-16 & $>16$ & $>8$ & $>16$ & 2 & $\mathbf{F}$ & 7 & Dead \\
\hline CKpCR13 & 29-Mar-16 & $>16$ & $>8$ & $>16$ & 2 & M & 11 & Dead \\
\hline CKpCR14 & 16-Apr-16 & $>16$ & $>8$ & $>16$ & 2 & $\mathbf{F}$ & 8 & Alive \\
\hline CKpCR15 & 22-Mar-16 & $>16$ & $>8$ & $>16$ & 2 & M & 9 & Alive \\
\hline CKpCR16 & 26-Mar-16 & $>16$ & $>8$ & $>16$ & 2 & M & 7 & Dead \\
\hline CKpCR17 & 6-Apr-16 & $>16$ & $>8$ & $>16$ & 2 & $\mathbf{M}$ & 15 & Alive \\
\hline CKpCR18 & 30-Mar-16 & $>16$ & $>8$ & $>16$ & 2 & M & 7 & Alive \\
\hline CKpCR19 & 16-Apr-16 & $>16$ & $>8$ & $>16$ & 2 & M & 18 & Alive \\
\hline CKpCR20 & 13-Mar-16 & $>16$ & $>8$ & $>16$ & 2 & $\mathbf{F}$ & 13 & Alive \\
\hline CKpCR21 & 13-Mar-16 & $>16$ & $>8$ & $>16$ & 2 & $\mathbf{F}$ & 21 & Alive \\
\hline CKpCR22 & 19-Apr-16 & $>16$ & $>8$ & $>16$ & 2 & $\mathbf{M}$ & 6 & Dead \\
\hline CKpCR23 & 12-Apr-16 & $>16$ & $>8$ & $>16$ & 2 & $\mathbf{F}$ & 16 & Alive \\
\hline CKpCR24 & 10-Apr-16 & $>16$ & $>8$ & $>16$ & 2 & M & 4 & Alive \\
\hline CKpCR25 & 10-Apr-16 & $>16$ & $>8$ & $>16$ & 2 & M & 10 & Alive \\
\hline CKpCR26 & 26-Mar-16 & $>16$ & $>8$ & $>16$ & 2 & $\mathbf{F}$ & 15 & Alive \\
\hline CKpCR27 & 12-Apr-16 & $>16$ & $>8$ & $>16$ & 2 & $\mathbf{M}$ & 10 & Dead \\
\hline CKpCR28 & 28-Mar-16 & $>16$ & $>8$ & $>16$ & 2 & M & 7 & Dead \\
\hline${ }^{\#}$ EKpER1 & 4-Apr-16 & $>16$ & $>8$ & $>16$ & 2 & - & - & - \\
\hline${ }^{\#}$ EKpER2 & 4-Apr-16 & $>16$ & $>8$ & $>16$ & 2 & - & - & - \\
\hline
\end{tabular}

\section{CONCLUSION}

In conclusion, this study showed the emergence of bacterial resistance to last resort antibiotic, especially in the intensive care unit of the hospital is of great concern and required judicious use of antibiotic with proper susceptibility analysis as well as continuous surveillance to minimize the emergence of new clones.

\section{ACKNOWLEDGEMENT}

The authors are grateful to the authority, faculties and staffs of TATA main hospital, Jamshedpur for providing laboratory facilities to carry out this study.

\section{REFERENCES}

[1] World Health Organization. Antimicrobial resistance: Global report on surveillance. Geneva: WHO, 2014.

[2] Podschun R, Ullmann U. Klebsiella spp. as nosocomial pathogens: epidemiology, taxonomy, typing methods, and pathogenicity factors. 
Clinical Microbiology Review, 11, 1998, 589-603.

[3] Yu VL, Hansen DS, Ko WC, Sagnimeni A, Klugman KP, von Gottberg A, Goossens H, Wagener MM, Benedi VJ. Virulence characteristics of Klebsiella and clinical manifestations of $K$. pneumoniae bloodstream infections. Emerging Infectious Disease, 13, 2007, 986-993.

[4] Boucher HW, Talbot GH, Bradley JS, Edwards JE, Gilbert D, Rice LB, Scheld M, Spellberg B, Bartlett J. Bad bugs, no drugs: no ESKAPE! An update from the Infectious Diseases Society of America. Clinical Infectious Disease, 48, 2009, 1-12.

[5] Sankar, MJ, Agarwal R, Deorari AK, Paul VK. Sepsis in the newborn. Indian Journal of Pediatrics, 75, 2008, 261-266.

[6] Borgia S, Lastovetska O, Richardson D, Eshaghi A, Xiong J, Chung C, Baqi M, McGeer A, Ricci G, Sawicki R, Pantelidis R, Low DE, Patel SN, Melano RG. Outbreak of carbapenem-resistant

Enterobacteriaceae containing blaNDM-1, Ontario, Canada. Clinical
Infectious Disease, 55, 2012, e109e117.

[7] Poirel L, Lascols C, Bernabeu S, Nordmann P. NDM-1-producing Klebsiella pneumoniae in Mauritius. Antimicrobial Agents and Chemotherapy, 56, 2012, 598-599.

[8] Teo JWP, Kurup A, Lin RTP, Hsien KT. Emergence of clinical Klebsiella pneumoniae producing OXA-232 carbapenemase in Singapore. New Microbes and New Infection, 1, 2013, 13-15.

[9] Wener KM, Schechner V, Gold HS, Wright SB, Carmeli Y. Treatment with fluoroquinolones or with $\hat{\mathrm{I}}^{2}-$ lactam-Îl'-lactamase inhibitor combinations is a risk factor for isolation of extended-spectrum- $-^{2}$ lactamase-producing Klebsiella species in hospitalized patients. Antimicrobial Agents and Chemotherapy, 54(5), 2010, 2010-6.

[10] Li J, Nation RL, Turnidge JD, Milne RW, Coulthard K, Rayner CR, Paterson DL. Colistin: the reemerging antibiotic for multidrugresistant Gram-negative bacterial infections. Lancet Infectious Disease 6, 2006, 589-601. 
[11] Brink AJ, Richards GA, Colombo G, Bortolotti F, Colombo P, Jehl F. Multi-component antibiotic substances produced by fermentation: implications for regulatory authorities, critically ill patients and generics. International Journal of Antimicrobial Agents, 43, 2014, 1-6.

[12] Bergen PJ, Landersdorfer CB, Zhang J, Zhao M, Lee HJ, Nation RL, Li J. Pharmacokinetics and pharmacodynamics of 'old' polymyxins: what is new? Diagn Microbiol Infect Dis 2012; 74: 213 223.

[13] Ah YM, Kim AJ, Lee JY. Colistin resistance in Klebsiella pneumoniae. International Journal of Antimicrobial Agents, 44, 2014, 815.

[14] Singh SK, Mishra M, Sahoo M, Patole S, Mohapatra H. Efflux mediated colistin resistance in diverse clones of Klebsiella pneumoniae from aquatic environment. Microbial Pathogenesis, 102, 2016, 109-112.

[15] Cannatelli A, D'Andrea MM, Giani T, Di Pilato V, Arena F, Ambretti S, Gaibani P, Rossolini GM. In vivo emergence of colistin resistance in Klebsiella pneumoniae producing KPC-type carbapenemases mediated by insertional inactivation of the PhoQ/PhoP mgrB regulator. Antimicrobial Agents and Chemotherapy, 57, 2013, 55215526.

[16] Cheng YH, Lin TL, Pan YJ, Wang YP, Lin YT, Wang JT. Colistin resistance mechanisms in Klebsiella pneumoniae strains from Taiwan. Antimicrobial Agents and Chemotherapy, 59, 2015, 29092913.

[17] Liu YY, Wang Y, Walsh TR, Yi LX, Zhang R, Spencer J, Doi Y, Tian G, Dong B, Huang X, Yu LF, Gu D, Ren H, Chen X, Lv L, He D, Zhou H, Liang Z, Liu JH, Shen J. Emergence of plasmid-mediated colistin resistance mechanism MCR1 in animals and human beings in China: a microbiological and molecular biological study. Lancet Infectious Disease, 16, 2016, 161168.

[18] Majhi JK, Mishra AK, Behera A. A study on outbreak of carbapenem plus colistin-resistant Klebsiella pneumoniae sepsis in newborns in a 
nursery of a tertiary care hospital. Journal of Evidence Based Medical Healthcare, 4, 2017,119-122.

[19] Jorgensen JH, Turnidge JD. Susceptibility test methods: dilution and disk diffusion methods: In Jorgensen J, Pfaller M, Carroll K, Funke G, Landry M, Richter S, Warnock D, editors, Manual of Clinical Microbiology, $11^{\text {th }}$ ed: ASM Press, Washington, DC. 2015, pp. 1253-1273. dOI:

10.1128/9781555817381.ch71

[20] Patel JB, Jeff Alder FRC, Bradford AP, Eliopoulos MG, Hardy JD. Performance Standards for Antimicrobial Susceptibility Testing; Twenty-Fourth Informational Supplement, M100S24. Wayne, PA 2014. https://kaldur.landspitali.is/focal/gae dahandbaekur/gnhsykla.nsf/5e27f2e 5a88c898e00256500003c98c2/9c4f 4955ccb9f8100025751a0046b075/\$ FILE/ATTJRR31.

[21] Yilmaz NO, Agus N, Bozcal E, Oner O, Uzel A. Detection of plasmid-mediated AmpC $\hat{\mathrm{I}}^{2}$ lactamase in Escherichia coli and Klebsiella pneumoniae. Indian
Journal of Medical Microbiology, 31, 2013, 49-53.

[22] Munoz MA, Welcome FL, Schukken YH, Zadoks RN. Molecular epidemiology of two Klebsiella pneumoniae mastitis outbreaks on a dairy farm in New York State. Journal of Clinical Microbiology, 45, 2007, 3964-3971.

[23] Diancourt L, Passet V, Verhoef J, Grimont PAD, Brisse S. Multilocus sequence typing of Klebsiella pneumoniae nosocomial isolates. Journal of Clinical Microbiology, 43, 2005, 4178-4182.

[24] Antoniadou A, Kontopidou F, Poulakou G, Koratzanis E, Galani I, Papadomichelakis E, Kopterides P, Souli M, Armaganidis A, Giamarellou H. Colistin-resistant isolates of Klebsiella pneumoniae emerging in intensive care unit patients: first report of a multiclonal cluster. Journal of Antimicrobial Chemotherapy, 59, 2007, 786-790.

[25] Olaitan AO, Diene SM, Kempf M, Berrazeg M, Bakour S, Gupta SK, Thongmalayvong B, Akkhavong K, Somphavong S, Paboriboune P, Chaisiri K, Komalamisra C, Adelowo OO, Fagade OE, Banjo 
OA, Oke AJ, Adler A, Assous MV, Morand S, Raoult D, Rolain JM. Worldwide emergence of colistin resistance in Klebsiella pneumoniae from healthy humans and patients in Lao PDR, Thailand, Israel, Nigeria and France owing to inactivation of the $\mathrm{PhoP} / \mathrm{PhoQ}$ regulator mgrB: an epidemiological and molecular study. International Journal of Antimicrobial Agents, 44, 2014, 500-507.

[26] Singh SK, Mishra M, Sahoo M, Patole S, Mohapatra H. Efflux mediated colistin resistance in diverse clones of Klebsiella pneumoniae from aquatic environment. Microbial Pathogenesis 102, 2017, 109-112.

[27] Gu DX, Huang YL, Ma JH, Zhou HW, Fang Y, Cai JC, Hu YY, Zhang R. Detection of colistin resistance gene mor-1 in hyper virulent Klebsiella pneumoniae and Escherichia coli isolates from an infant with diarrhea in China. Antimicrobial Agents and Chemotherapy, 60, 2016, 50995100.

[28] Giordano C, Barnini S, Tsioutis C, Chlebowicz MA, Scoulica EV,
Gikas A, Rossen JW, Friedrich AW, Bathoorn E. Expansion of KPCproducing Klebsiella pneumoniae with various mgrB mutations giving rise to colistin resistance: the role of ISL3 on plasmids. International Journal of Antimicrobial Agents, 51(2), 2018, 260-5.

[29] Cannatelli A, Di Pilato V, Giani T, Arena F, Ambretti S, Gaibani P, D'Andrea MM, Rossolini GM. In vivo evolution to colistin resistance by PmrB sensor kinase mutation in KPC-producing Klebsiella pneumoniae is associated with lowdosage colistin treatment. Antimicrobial Agents and Chemotherapy, 58, 2014, 43994403.

[30] Mammina C, Bonura C, Di Bernardo F, Aleo A, Fasciana T, Sodano C, Saporito MA, Verde MS, Tetamo R, Palma DM. Ongoing spread of colistin-resistant Klebsiella pneumoniae in different wards of an acute general hospital, Italy, June to December 2011. Euro Surveillance, 17, 2011, 1-4.

[31] Lascols C, Peirano G, Hackel M, Laupland KB, Pitout JDD. Surveillance and molecular 
epidemiology of Klebsiella

pneumoniae that produce

carbapenemases; the first report of

OXA-48-like enzymes in North

America. Antimicrobial Agents and

Chemotherapy, 57, 2012, 130-6.

[32] Mathur P, Veeraraghavan B, Ragupathi NKD, Inbanathan FY, Khurana S, Bhardwaj N, Kumar S, Sagar S, Gupta A. First Report on a Cluster of Colistin-Resistant Klebsiella pneumoniae Strains Isolated from a Tertiary Care Center in India: Whole-Genome Shotgun Sequencing. Genome Announcement, 5, 2017, e0146601416. 